\title{
Combining research techniques to improve quality service in hospitality
}

\author{
-Mar Vila, Xari Rovira, Gerard Costa \\ ESADE, Universitat Ramon Llull, Barcelona, Spain \\ -Ricard Santoma \\ Turisme Sant Ignasi, Universitat Ramon Llull, Barcelona, Spain
}

\begin{abstract}
Hospitality research includes many studies that combine and revisit the quantitativequalitative debate, and review the arguments for and against using mixed-methods. The aim of this paper is to demonstrate the application of qualitative methodologies based on the combination of techniques which also include quantitative elements in addition to those pertaining to qualitative techniques. The research aims to specifically identify the most important managerial factors which, from the point of view of hotel chain executives, serve to improve the quality of the service they provide. The techniques used are concept mapping and qualitative optimization, both of which are qualitative methodologies though they include quantitative elements to overcome the subjectivity deficits typically found in qualitative methodologies. In addition, the combination of both techniques leads to greater precision of the results obtained. Our methodological proposal combines concept mapping with qualitative optimisation, thereby improving the prioritisation and hierarchical ordering of the ideas obtained and structured. Instead of working with each cluster's average score in terms of importance (as defined within the concept mapping model), our contribution is based on prioritising these based on their distance to the optimal reference. This allows for experts' evaluations of each idea in terms of its importance to not be strictly quantitative, that is, the experts are not obligated to assign numbers to their evaluations; rather, they can assess ideas based on qualitative labels.
\end{abstract}

\section{KEYWORDS}

Mixed-methodology, concept-mapping, qualitative optimization, hospitality, quantitativequalitative methodologies, quality service

\section{Introduction}

Any decision in terms of research methodology and techniques, especially a choice between quantitative or qualitative techniques, implies a trade-off between data integrity and currency.

In a general sense, qualitative techniques are appropriate to explore ideas, theories or constructs which haven't been defined as yet, while quantitative techniques measure the degree to which those ideas are applied or not.

As Strauss and Corbin (1998) propose when talking about qualitative methodologies, we refer to any type of research which produces results that are not obtained through statistical or mathematical formulas during the interpretation process to reveal underlying concepts or relationships. This does not mean that qualitative methodologies cannot quantify or statistically process the results obtained; rather, their objective is different. Deciding to apply a qualitative methodology occurs when it is felt that there isn't a sufficiently developed body of knowledge about the subject at hand (Strauss and Corbin 1998; Miles and Huberman 1994). The desired result is theory-building. This requires describing, classifying and comparin data (Bonoma 1985; 
Patton 2002). Qualitative research is broadly accepted when its aim is to discover new concepts, determine how the latter are organised and structured in order to explain them or to develop a theoretical framework (Flick 1998; Patton 2002; Marshall and Rossman 1989), in particular when the research object refers to human and social problems and when the objective is to discover important questions, processes and relations. For all these, qualitative methodologies have different theoretical and technical orientations as summarised by Miles and Huberman (1994) (Fig. 1).

\begin{tabular}{|c|c|c|c|}
\hline \multicolumn{4}{|c|}{ The research interest is in... } \\
\hline \multirow{8}{*}{$\begin{array}{l}\text { The } \\
\text { characteristics } \\
\text { of language }\end{array}$} & \multirow{3}{*}{$\begin{array}{l}\text { As } \\
\text { communicati } \\
\text { on }\end{array}$} & Content & Content analysis \\
\hline & & \multirow[b]{2}{*}{ Process } & Discourse analysis \\
\hline & & & \multirow{2}{*}{ Ethnography of communication } \\
\hline & \multirow{5}{*}{ As culture } & \multirow{3}{*}{ interactive } & \\
\hline & & & $\begin{array}{l}\text { Symbolic interactionism, } \\
\text { ethnomethodology }\end{array}$ \\
\hline & & & \multirow{2}{*}{ Structural ethnography } \\
\hline & & \multirow{2}{*}{ Cognitive } & \\
\hline & & & Ethnoscience \\
\hline \multirow{9}{*}{$\begin{array}{l}\text { The discovery } \\
\text { of regularities }\end{array}$} & \multirow{5}{*}{\multicolumn{2}{|c|}{$\begin{array}{l}\text { Identification (and } \\
\text { categorisation) of elements, } \\
\text { and exploration of their } \\
\text { connections }\end{array}$}} & Transcendental realism \\
\hline & & & Ethnographic content analysis \\
\hline & & & Event structure analysis \\
\hline & & & Ecological psychology \\
\hline & & & Grounded theory \\
\hline & & $\begin{array}{l}\text { In } \\
\text { conceptualizatio } \\
\mathrm{n}\end{array}$ & Phenomenography \\
\hline & $\begin{array}{l}\text { Discerning } \\
\text { of patterns }\end{array}$ & $\begin{array}{l}\text { As } \\
\text { deficiencies, } \\
\text { ideologies }\end{array}$ & $\begin{array}{l}\text { Qualitative evaluation, action } \\
\text { research, } \\
\text { collaborative research, } \\
\text { critical / emancipatory } \\
\text { research }\end{array}$ \\
\hline & & As culture & Holistic ethnography \\
\hline & & As socialization & $\begin{array}{l}\text { Educational ethnography, } \\
\text { naturalistic } \\
\text { inquiry }\end{array}$ \\
\hline \multirow{3}{*}{$\begin{array}{l}\text { The } \\
\text { comprehensio } \\
n \text { of the } \\
\text { meaning of } \\
\text { text / action }\end{array}$} & \multicolumn{2}{|c|}{$\begin{array}{l}\text { Discerning of themes } \\
\text { (commonalities } \\
\text { and uniqueness) } \\
\end{array}$} & Phenomenology \\
\hline & \multirow{2}{*}{\multicolumn{2}{|c|}{ Interpretation }} & Case study, life history \\
\hline & & & Hermeneutics \\
\hline \multirow{3}{*}{\multicolumn{3}{|c|}{ Reflection }} & Educational connoisseurship \\
\hline & & & Reflective phenomenology \\
\hline & & & Heuristic research \\
\hline
\end{tabular}

Fig. 1 Qualitative research reference framework. Source: adapted from Miles and Huberman (1994)

For their part, the primary objective of quantitative methodologies is to generalise and universally apply the results obtained. The main challenge implied, however, is the definition of a starting point outside the research, that is, a theory, construct or model already established and accepted by the scientific community. Quantitative methodologies and their respective techniques can be used to understand the underlying relationships in the area of research (Easterby-Smith and Lowe 1991; Flick 1998); they can also be useful to answer specific research questions (Morse 1994), to reveal relationships which are not evident for the researcher using other techniques and/or to reinforce theories suggested by qualitative techniques (Eisenhardt 1989).

When comparing qualitative and quantitative techniques, the latter overcome the dèficits of the former in terms of subjectivity, the depth of the results and their generalisation; however, they require a prior theory which has to be measured or contrasted. By contrast, qualitative techniques can be used to explore areas for which there is little information or for which there is no sufficiently developed body of knowledge (Strauss and Corbin 1998). In this respect, quantitative techniques often require more flexible postures leading to a more creative type of science (Beeril 1994). 
Not only the research objective determines the choice of one methodology over the other; additional factors include the study object and the incorporation of contextual conditions because many phenomena, due to their complexity, cannot be explained in isolation and the quantitative methodology cannot be designed according to a clear cause and effect model. Flick (1998) points out that,while it is possible to include contextual conditions in multi-level analysis quantitative designs, the necessary methodological abstraction makes it difficult to re-introduce the daily situations included in the study with the research results; however, qualitative research can include this complexity and doesn't require reducing variables to the study object. Lastly, it's worth mentioning that, when selecting the methodology, the researcher also has to bear in mind the recipient of the research results. For example, in the management field, qualitative research results are more readily accepted by executives than results from quantitative surveys, primarily due to the intensity of the data in the latter (Goulding 2002).

The debate in the 1970s and 1980s regarding the use of mixed quantitative/qualitative methods continues to this day, and some authors still feel that this combined technique doesn't make sense because each method responds to a different paradigm, positivism versus constructivism. Others argue that both methods can be complemented while not obviating the nature of each and clearly establishing different objectives (Sale et al. 2002). Parallel to this debate, research practice continues to include the use of mixed methods, whether this is the complementary use of quantitative techniques which help to better understand qualitative results in terms of the underlying relationships in the research area (Easterby-Smith and Lowe 1991; Flick 1998; Morse 1994) or, inversely, the use of qualitative techniques to explain relationships discovered through quantitative analyses (Eisenhardt 1989; Harris and Piercy 1999). In both cases, there is an added difficulty associated to the different paradigma on which each methodology is based, that, is, the sample, as argued by Morse (1994), given that the nature of the qualitative sample (generally small and previously selected) doesn't respect size and randomness assumptions found in quantitative research.

The aim of this paper is to demonstrate the application of qualitative methodologies based on the combination of techniques which also include quantitative elements in addition to those pertaining to qualitative techniques. The research aims to specifically identify the most important managerial factors which, from the point of view of hotel chain executives, serve to improve the quality of the service they provide. The techniques used are concept mapping and qualitative optimization, both of which are qualitative methodologies though they include quantitative elements to overcome the subjectivity deficits typically found in qualitative methodologies. In addition, the combination of both techniques leads to greater precision of the results obtained.

In Sect. 2 we propose a combination of quantitative and qualitative techniques, describing the specific two we use in this research: concept mapping (Trochim 1989) and qualitative optimization (Sánchez et al. 2007). In Sect. 3 we describe the study carried out on Spanish hotel chain quality, providing some results. In the last section we present some conclusions as well as questions to be addressed in future research.

\section{Combination of qualitative and quantitative techniques}

In this section we describe two techniques, concept mapping and qualitative optimization, framed within the qualitative paradigm but which also include some quantitative techniques in their design, the aim being to add greater objectivity to these results in addition to the qualitative elements. Firstly, concept mapping uses qualitative and quantitative techniques to map interrelated concepts (Rosas and Camphausen 2007). This is a suitable technique when objective opinions or ideas are required from a single sample. Qualitative optimization (Sánchez et al. 2007), for its part, allows researchers to create hierarchies of the ideas obtained by applying qualitative reasoning techniques. It is based on the order-of-magnitude model (Travé and Dague 2003) which, by calculating distances, enables this hierarchy of results to be determined. In this sense, qualitative optimization enriches the concept map conceptualisation process through the hierarchy of ideas. For this reason we propose combining both of these techniques. 


\subsection{Concept mapping}

Concept mapping was originally developed by Trochim (1989) to respond to conceptualisation needs based on the objectification of opinions and ideas from a group of experts. It uses a qualitative methodology which incorporates statistical techniques, such as multidimensional scaling and cluster analyses.

Numerous authors have used this technique to define the concepts they wanted to research. Trochim et al. (2004), for example, described the case of the Hawaiian health department in which they used this technique to determine how a community affected an individual's behaviour with respect to tobacco use, nutrition and physical exercise. Nabitz et al. (2001) used this technique to reformulate the EFQM Model's content, weights and formulation. Rosas and Camphausen (2007) describe the different areas in which the concept mapping technique has been applied, highlighting, amongst others, the development of logical models (Yampolskaya et al. 2004), determinin quality criteria (Barth 2004) and the analysis of statistical responses (Jackson and Trochim 2002). In the tourism field, Bigné et al. (2002) applied this technique in their study to identify what factors determined client loyalty towards travel agents. Similarly, Calvo de Mora et al. (2006) used concept mapping to determine the elements that tourism programmes at universities have to include as seen from their prospective employers' perspective.

The concept mapping technique is based on six steps (Fig. 2), as originally proposed by Trochim (1989). However, we should note that adaptations can be seen in research practice to provide a better fit with the researchers' objectives.

\subsubsection{Step 1: preparation}

The concept to be researched is defined and the people who will participate in the brainstorming process are selected. To set the objective, for example, Bigné et al. (2002) reviewed existing literature and interviewed various experts to clarify different concepts to be used throughout the process. Nabitz et al. (2001) used the EFQM Model as the starting point and, as such, the objective was already delimited before the research was carried out. How participants are selected varies depending on the study. For best results, Trochim (1989) recommends a group of 8-15 participants who are as heterogeneous as possible. Bigné et al. (2002) chose a group of 15 clients for their study while Rosas and Camphausen (2007) worked with a group of 14 executives and experts. By contrast, Calvo de Mora et al. (2006) began with a group of 10 participants, including hotel and travel agent employees. 


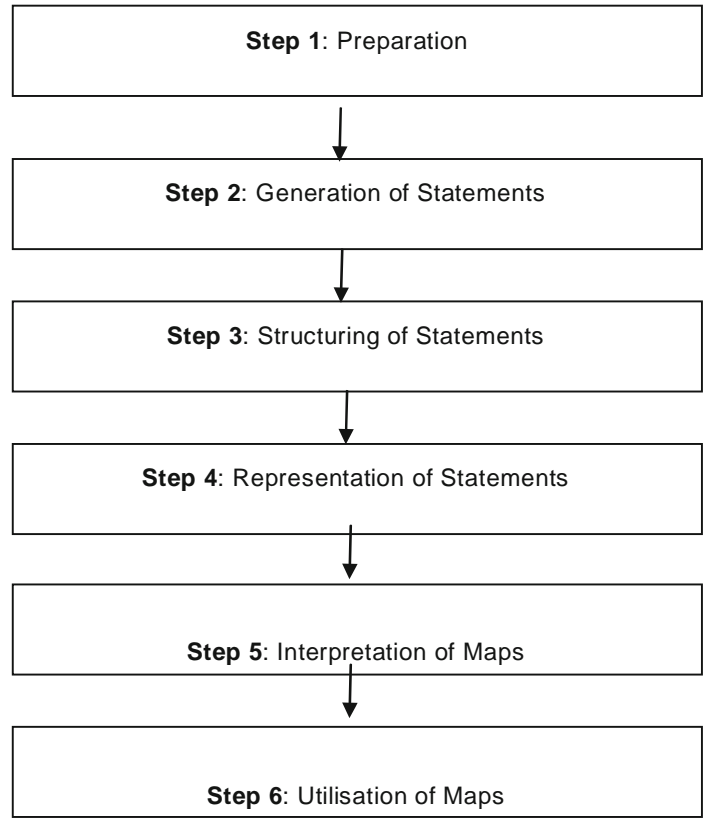

Fig. 2 The concept mapping process. Source: Trochim (1989)

\subsubsection{Step 2: generation of statements}

The aim of this step is to ask participants to brainstorm and gather their ideas regarding the concept under study. The primary goal is to generate the maximum number of ideas possible. These ideas are then filtered at the end of the step. It's worth noting that Nabitz et al. (2001) did not organise a brainstorming session as they began with an established model and the object of their analysis as mentioned above. Simpson (1994) also worked with a focus group contacted by means of questionnaires.

\subsubsection{Step 3: structuring of statements}

Once ideas have been generated, participants are asked to group them together using their own criteria. However, they must comply with certain rules: for example, they cannot group all the ideas together into a single group; there cannot be the same number of groups as there are ideas; and each idea can only be included in one group.

Afterwards, participants are asked to evaluate how important each idea is with respect to the concept being studied. For this, Trochim proposes that participants be asked to rate each idea using a 1-to-5 Likert scale, where 1 represents that the idea contributes little to the concept and 5 that it contributes a lot.

\begin{tabular}{llllll}
\hline & 1 & 2 & 3 & 4 & 5 \\
\hline 1 & 1 & 1 & 1 & 0 & 0 \\
2 & 1 & 1 & 1 & 0 & 0 \\
3 & 1 & 1 & 1 & 0 & 0 \\
4 & 0 & 0 & 0 & 1 & 1 \\
5 & 0 & 0 & 0 & 1 & 1 \\
\hline
\end{tabular}

Table 1 Example of an $S_{5} 5$ similarity matrix. Source: The autors based on Trochim (1989) 
Structuring begins with a similarity matrix $S_{N \times N}$ for each of the participants, with "N" rows and "N" columns, "N" representing the total number of ideas generated during the brainstorming session. Where ideas " $\mathrm{i}, \mathrm{j}$ " $\left(\mathrm{S}_{i, j}\right)$ intersect, a "1" is introduced if the participant included both ideas in the same group. Contrarily, a "0" is introduced if that participant did not include both ideas in the same group. The value of the main diagonal is also a "1" given that it is where an idea in a given row coincides with the same idea situated in the column (Table 1).

Next, all the individual $S_{N \times N}$ similarity matrices for the Group $T_{N \times N}$ (grouping matrix) are added together. This grouping matrix consists of as many rows and columns as the number of ideas generated. The number in each intersection will vary from "0" to " $M$ ", representin the number of participants that have included the two ideas in the same group, independently of the criteria used for that favourable grouping, being $\mathrm{M}$ the total number of participants. The value of thematrix' main diagonal will be equal to the total number of participants taking part in this step of the research (Trochim 1989). The grouping matrix provides information about how the participants think ideas should be grouped. A high value in the intersection between two ideas implies that a large number of participants have grouped the two together and, as such, they are very close conceptually.

\subsubsection{Step 4: representation of statements}

The data gathered in the grouping matrix in the previous step are processed using the multidimensional scaling technique to obtain a map representing each of the ideas. When two ideas are close together on this map, it implies that a lot of participants have grouped the two ideas together and that, as such, they are related. If two ideas are far apart on the map, it means that few participants felt that they were in the same group of ideas. Multidimensional scaling is a multivariate statistical technique which, based on a $N \times N$-size grouping matrix, spatially represents the distance between the idees included in the matrix (Hair et al. 2006). Multidimensional scaling allows researchers to determine the number of dimensions which the set of points on the map will represent. If a single dimension solution is required, the points can be placed on a straight line. The bi-dimensional solution places the set of points on a plane. More dimensions can be used, though it is difficult to interpret and represent them. This is why concept maps tend to use the bi-dimensional solution. Kruskal andWish (1978) indicate that, generally, it is easier to work with certain configurations along two dimensions than across more; for example, when the researcher wants to carry out a cluster analysis based on a multidimensional scaling study, using a two-dimension configuration is much more useful than any other type.

A cluster analysis is then carried out on the data obtained, using the same co-ordinates as those from the multidimensional scaling study in order to determine which different groups of ideas explain the concept being studied. Cluster analyses examine the information and organise data by homogenous concept groups, using the point map obtained from the multidimensional scaling technique (Trochim 1989). In principle, cluster analysis considers each item to be its own cluster, providing a solution with "N" clusters. For each type of analysis, Ward's Algorithm (Ward 1963) combines the cluster to agglomerate ideas, optimising the sum of distances squared for each element at the centre of the cluster. As the ideas are being grouped together, the number of clusters diminishes until there is only one left. The researcher has to determine the ideal number of clusters according to his/her objectives, and there is no single method to reach this number (Hair et al. 2006).

\subsubsection{Step 5: interpretation of maps}

The aim in this step is to show the group of participants the maps obtained in the previous steps and to ask them to interpret these maps. Previously, a descriptive label has been added to each group resulting from the cluster analysis. During this step, participants can join or separate clusters. They can even decide to move an idea into another cluster if they feel it is more appropriate. Consensus is the most important criteria in this part of the research. 


\subsubsection{Step 6: utilitsation of maps}

Lastly, the maps are used as a graphic representation of the experts' opinion regarding the concept under study.

\subsection{Qualitative optimization}

Qualitative optimization is a technique which allows information to be prioritised based on ordinal data. This optimization process allows a set of features (or ideas, in our case) to be ordered based on how a group of experts has evaluated them, using an ordinal scale (Sánchez et al. 2007). These evaluations stem from k-dimensional labels belonging to an absolute ordersof-magnitude space.

Sánchez et al. (2007) described this technique and applied it to a specific situation: managers in a given retail firm evaluating performance features describing the points of sale, first, in terms of the features' importance for the point of sales' success and, second, the current performance of that feature within the company. After this qualitative optimization process, Sánchez was able to rank the features from both points of view and to compare the real situation with the ideal one in the company.

Here we summarise the most important aspects of this technique. A one-dimensional absolute orders-of-magnitude space (Travé and Dague 2003) consists of a finite number of qualitative labels which correspond to an ordinal measurement scale. The number of labels chosen to describe a problem is not set and depends on the characteristics of the represented variables (Agell and Piera 1992; Agell et al. 2000).

Next we define what we understand as an orders-of-magnitude space OM (n) of " $n$ " granularity. A finite, ordered set of labels $\mathrm{S} *=\left\{\mathrm{B} 1, \ldots, \mathrm{B}_{n}\right\}$ is considered in which each of the terms corresponds to a linguistic term. As such, $\mathrm{B} 1<\ldots<\mathrm{B}_{n}$ can represent, for example, "very little" < "little" < "more or less" < "some" < "a lot" and in which the S* elements are known by their basic labels. The complete universe of descriptors of the orders-of-magnitude space OM(n) would be represented by the set $\mathrm{S}=\mathrm{S} * \mathrm{U}\left\{\left[\mathrm{B}_{i}, \mathrm{~B}_{j}\right], \mathrm{B}_{i}, \mathrm{~B}_{j} \in \mathrm{S} * \mathrm{i}<j\right\}$, where the label $\left[\mathrm{B}_{i}, \mathrm{~B}_{j}\right]$, is defined as the set $\left\{\mathrm{B}_{i}, \mathrm{~B}_{i+1}, \ldots, \mathrm{B}_{j}\right\}$ of basic labels situated between $\mathrm{B}_{i}$ and $\mathrm{B}_{j}$. For example, if $\mathrm{B}_{i}=$ "little" and $\mathrm{B}_{j}=$ "some" (from the previous example), the label $\left[\mathrm{B}_{i}, \mathrm{~B}_{j}\right]$ could be expressed as "between little and some" (Fig. 3). The number "n" of basic labels which defines the OM(n) space is referred to as granularity. The order in the set of basic labels induces a partial order in S: $(\mathrm{S} \leq)$.

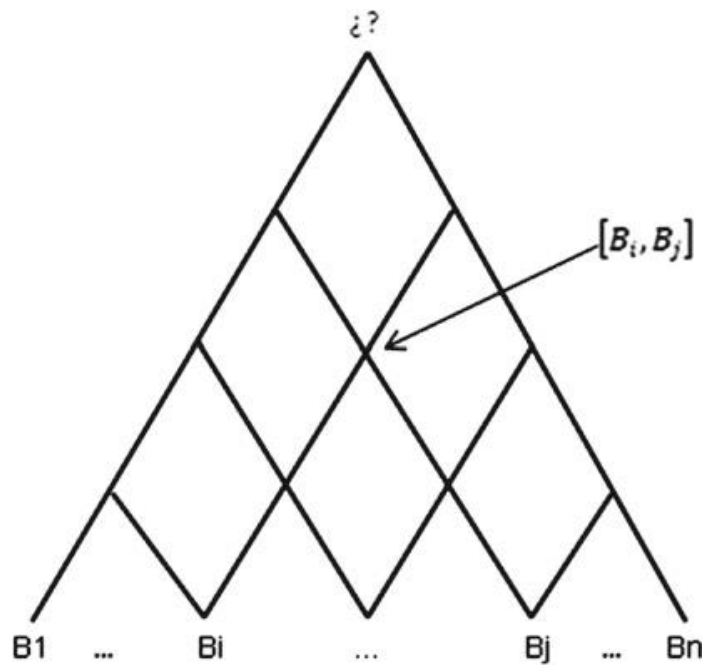

Fig. 3 Complete OM (n) descriptor universe. Source: The authors based on Trochim (1989) 
In the prioritisation process, in keeping with the methodology described by Sánchez et al. (2007), each of the "p" features (hereafter, referred to as "ideas" as corresponds to the application of this technique described in the following section) is characterized by the judgment of " $k$ " evaluators using the qualitative levels in the OM(n). As such, each idea "i", with $\mathrm{i} \in\{1, \ldots, \mathrm{p}\}$, is represented by a k-dimensional label $\mathrm{E}(\mathrm{i})=\left(\mathrm{e}_{1}{ }_{1} \ldots, \mathrm{e}_{k}{ }_{k}\right)$, that is, a set of " $\mathrm{k}$ " qualitative labels, each one associated to the evaluation given by each of the " $\mathrm{k}$ " experts regarding the idea " $\mathrm{".} \mathrm{If} \mathrm{we} \mathrm{call} \mathrm{the} \mathrm{set} \mathrm{of} \mathrm{all} \mathrm{the} \mathrm{k}$-dimensional labels " $\mathrm{E}=\mathrm{S} \times$. . . $\times \mathrm{S}$ ", the defined partial order in " $\mathrm{S}$ " can be extended to the Cartesian product "E" and it can be interpreted such that, if two k-dimensional labels are comparable, it means that the idea that corresponds to one of them has received a better (or worse) evaluation than the other.

The ranking process of the ideas based on labels, with each k-dimensional label representin one of the ideas, is as follows:

- A distance "d" is established in the set "E" of k-dimensional labels.

- A "reference label" is built (in our case, we'll call it the "optimal idea" and refer to it as

"O"). This reference label is the supreme label with respect to the order established in "E" regarding the ideas to be ranked.

- Each k-dimensional label is assigned its distance to the "optimal idea" built in the second point, that is, $\mathrm{d}_{i}=\mathrm{d}(\mathrm{O}, \mathrm{E}(\mathrm{i})$ ), thus obtaining a totally ordered list of ideas.

- Lastly, if a subset of ideas is at the same distance to "O", the same process is applied to this set, as of the second point outlined above.

After completing the ranking process, if the idea "i" has a low $\mathrm{d}_{i}$, this means that many evaluators have placed it close to the optimal reference, while a high $\mathrm{d}_{i}$ implies that few evaluators consider it close to the optimal reference.

In the application described in the following section, what we evaluate is the importance of the ideas according to their impact on improving the service quality offered. As such, the lower the $\mathrm{d}_{i}$ value assigned to the idea, the more important it is to improving quality.

\section{Application to Spanish hotel quality management}

\subsection{Objectives}

After reviewing the existing literature on service quality management, we determined that there was a need to continue researching the concrete case of the hotel industry, in particular, the important factors affecting service quality management. Santomà and Costa (2008) analyse the articles published between 1990 and 2007 in journals of reference according to McKercher et al. (2006). They determined that research into hotel service quality could be divided into three groups: first, articles exploring the concept from a theoretical point of view; second, those focusing on total quality management and different application models; and, third, articles which attempt to measure service quality among service sector companyies with the respective authors' own models, predominantly SERVQUAL or specific adaptations for the hotel industry. In addition to revealing the particularities of the hotel industry's service quality, these studies have also demonstrated a positive relationship between service quality, client satisfaction, purchase intentions and future recommendations (Santomà and Costa 2008; Oh 1999; Olorunniwo et al. 2006), thus justifying the need to develop quality assurance policies within hotel industry firms.

The concern with quality in the Spanish hotel industry emerged in the early 1990s and grew stronger in the first decade of the new millennium as a need for differentiation due to changes in the environment and competitive pressure from new competitors in emergint travel destinations. To respond to this need, numerous initiatives have been launched from the public and private spheres. Public initiatives aim to establish general policies for the 
entire tourism and hotel industry to differentiate it as a quality destination. Private initiatives launched by the hotel chains themselves serve to differentiate their offer from both national and international competitors. As such, quality is a fundamental concern in these differentiation initiatives, and both the public and private sectors clearly wager on fomenting the imatge of quality and quality management among all tourism and hotel firms. This focus continues to prevail in Spanish tourism and hotel development plans and is demanded by the market itself (Vila 2004; Camisón et al. 2007; Puig-Durán 2006).

In practice, however, we can attest that quality management in the different Spanish hotels and hotel chains is relatively scarce. In particular, few have implemented a quality model created specifically for the hotel industry, with only $9 \%$ of hotels certified, and with more generic models, such as UNE-EN-ISO 9000, having been implemented even less frequently. This fact is not interpreted as a lack of interest among these firms, rather, a lack of fit between current models and hotels. For its part, the EFIM Model is also scarcely used within the Spanish hotel industry (Santomà 2008).

According to various studies, one of the reasons why there are few quality management or quality certification policies in the Spanish hotel industry is that different models don't correspond well to the specificities of the industry. This is why in this study we aim to explore those specificities. Concretely, we're interested in seeing which factors hotel managers feel are a key factor for quality management. Our research question is: "What management factors are considered as a priority to improve service quality among Spanish hotel chains?" The prioritised list of these aspects or factors aims to serve as the first step towards the creation of a quality management model specifically designed for the hotel industry.

\subsection{Methodology and results}

As our research aims to uncover new concepts, as is the case with the management factors that affect service quality in the Spanish hotel industry, the recommended techniques for this research are qualitative (Flick 1998; Patton 2002; Marshall and Rossman 1989). Concretely, with the aim of objectifying the results obtained as much as possible, we have used the concept mapping technique (Trochim 1989). We combine the latter with the qualitative optimization techniques described by Sánchez et al. (2007) to create an ordered list of results.

In keeping with Trochim (1989) recommendations regarding the use of the concept mapping technique, we carried out an initial review of the literature (also recommended by Nabitz et al. 2001). The aim was to clarify the concept of "quality" within the hotel industry. We then carried out four unstructured interviews to further clarify the concept to be developed. Afterwards, we selected the participants for the following steps, once more bearing in mind Trochim (1989) recommendations regarding participant heterogeneity (1989). As such, we selected a group of eight participants taking into consideration the following variables: participants' prior managerial experience in the industry, research carried out in the industry, knowledge of different Spanish hotel chains and their familiarity with the quality concepts as applied to the hotel industry. The session with participants was held on 19 July 2007, and it was videotaped.

We asked the selected group of experts the following question: "What hotel management aspects do you feel serve to improve service quality? "We then used the brainstorming technique for participants to explore this concept. During this step we counted on support from an expert on group dynamics, the aim being to optimise our results. This brainstorming session generated a list of 95 ideas. During the second step, we distributed the initial list of ideas to all the participants for them to revise and eliminate repetitions and possible errors. After this step, the list was reduced to a total of 84 items (Table 2). 
Third, we then asked participants to take part in two activities. The first consisted of evaluating the importance of each of the ideas mentioned during the brainstorming session in terms of its impact on improving service quality. Participants were asked to rate each item using a Likert scale ranging from 1 to 5 . These scores were later processed using a qualitative optimization technique. The second activity consisted of each participant grouping the ideas in terms of his/her own individual criteria regarding idea similarity or relationship, attempting to find a greater degree of abstraction than with the individualised items. For this, participants were sent a list with the 84 items by e-mail for them to group the ideas according to their own criteria while respecting the guidelines described in Sect. 2 above. Lastly, participants were asked to assign a descriptive label and name each of the groups they proposed. For this activity, two more participants were invited, as recommended by Trochim (1989).

The grouping matrix was then constructed and processed according to the Multidimensional Scaling (MDS) technique (using Alscal's method). The result was a point map in which each point represents an idea (Fig. 4). Once the map was created, a hierarchical clúster analysis was carried out using the distance between points based on their respective map co-ordinates resulting from the MDS analysis. As the experts did not agree on how to determine the ideal number of clusters (Hair et al. 2006), we decided to establish a number in which statistical groupings also had a coherent conceptual meaning with the ideas included in each groups. This was done in line with other similar studies (including, amongst others, Calvo de Mora et al. 2006; Nabitz et al. 2001 and Rosas and Camphausen 2007). The final result was a series of seven clusters ${ }^{1}$ to which each was assigned a name (Fig. 5):

Table 2 List of ideas from the brainstorming session

\begin{tabular}{|c|c|}
\hline 1 & Human resource motivation \\
\hline 2 & Specific training for the job post \\
\hline 3 & Administrative management of human resources \\
\hline 4 & Carry out focus groups with clients \\
\hline 5 & Use customer satisfaction surveys \\
\hline 6 & Process client data to segment them \\
\hline 7 & Brand positioning clarity \\
\hline 8 & Branding-related sales actions \\
\hline 9 & Establish strategic planning \\
\hline 10 & Establish operative planning for the functional areas \\
\hline 11 & Carry out focus groups and survey personnel \\
\hline 12 & Good workload distribution \\
\hline 13 & Cross-training for personnel \\
\hline 14 & Process management \\
\hline 15 & Existence of a commitment to the environment \\
\hline 16 & Supplier management \\
\hline 17 & Hotel segmentation based on clients \\
\hline 18 & Managers' commitment to the organisation \\
\hline 19 & Existence of leadership for quality \\
\hline 20 & Link between standards and business culture \\
\hline 21 & Corporate communications \\
\hline 22 & Internal communication \\
\hline 23 & External communication \\
\hline 24 & Establish corporate mission and vision \\
\hline 25 & Implement the mystery guest system \\
\hline 26 & Carry out interviews with clients \\
\hline 27 & Website design and maintenance \\
\hline 28 & Promotional material design \\
\hline 29 & Develop strategic alliances \\
\hline
\end{tabular}

\footnotetext{
${ }^{1}$ The following order does not imply a hierarchy.
} 
Vila, Mar; Rovira, Xari; Costa, Gerard; Santomà, Ricard. Combining Research Techniques to improve quality service in hospitality. Quality \& Quantity, 2012. Volume 46, issue 3, p. 795-812. DOI http://doi.org/10.1007/s11135-010-9414-9

Track and managed out-sourced services

Carry out joint actions with other business organisations

Building and facilities management

Internal departmental audits

Co-ordination systems between personnel and departments

Quality assurance certifications

Commitment to quality at the executive level

Commitment to quality at the shareholder level

Have a quality assurance department

Create departmental and inter-departmental improvement groups

Establish quality measurement and tracking systems

Quality and environmental objectives with timing, deadlines and measureable benchmarks

Budget available to improve quality

Develop and invest in worker safety and Health

Have personnel accountability tracking Systems

Apply CRM philosophy

Existence of a budget management System

Define competències and responsabilities

Define job positions

Define career plans

Define levels of quality

Vertical and horizontal training

Be proactive regarding information for the client

Client accessibility to information

Clients' physical access to the establishment

Be proactive with respect to the client

Have an agile system to gather, process and resolve complaints

Have loyalty-building programmes

Provide up-selling options

Existence of an empowerment policy for front-office staff

Develop the figure "duty manager"

Know how to take advantage of the improvement actions suggested by employees

Imitate others' improvement practices

Have good information systems available regarding market change

Have and use studies on the competition

Good inter-departmental cohesion

Balanced scorecard

Implement a culture focused on quality

Be convinced regarding quality

Define, encourage and maintain values

Employee satisfaction

Ability to influence environmental management

Relationship with public entities

Use of own information regarding clients

Maintain relationships with hotel-related schools

Innovate

Have human resource recruitment and selection systems

Develop employee recognition tools

Good remuneration system

Job stability

Chain financial management

Generic human resource training

Convince personnel

Fulfil current legislation

Analyse the organisation's strengths and weaknesses

Source: The authors 


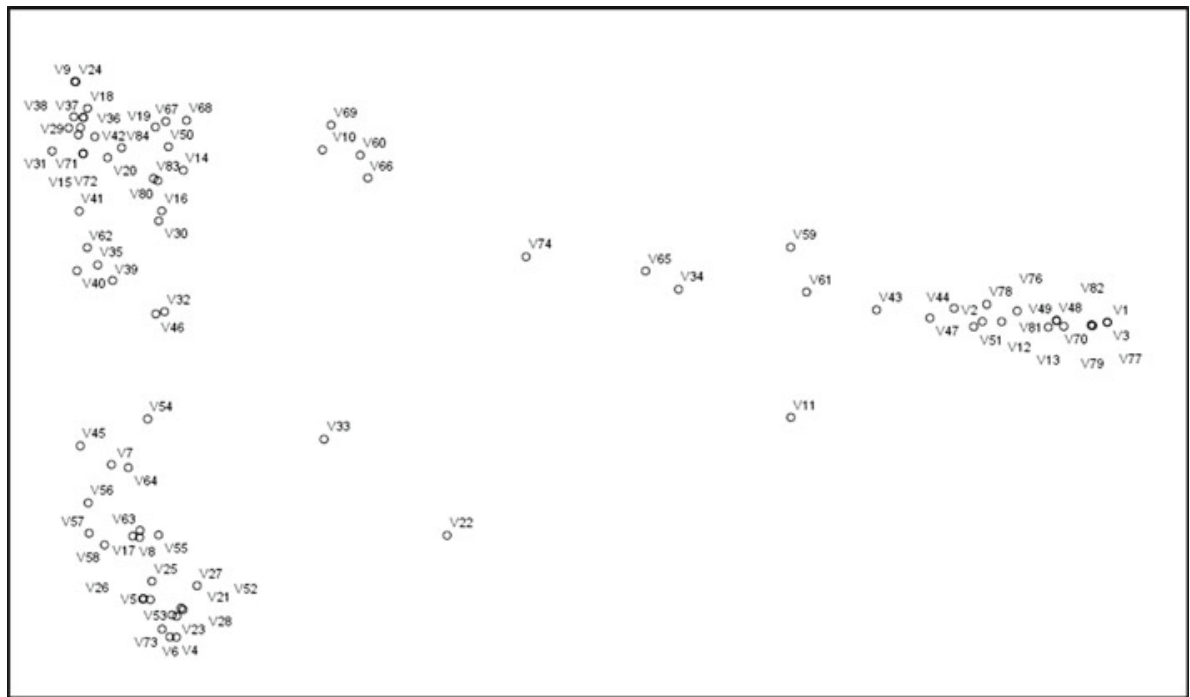

Fig. 4 MDS-generated point map. Source: Sánchez et al. (2007)

- The first cluster, Human Resource Management, consists of 21 ideas, the most numerous, and it includes all the factors related to strategic and operational personnel management.

- The second cluster, Client Information Management, consists of seven ideas and includes those related to specific activities and tools which imply the hotel chain having better information about the client.

- The third cluster, Strategic Marketing Management, consists of 15 ideas related to brand management, client segmentation and loyalty-building strategies.

- The fourth cluster, Internal Quality Management, includes 12 ideas and refers to factors related to the operational management of quality within hotel chains.

-The fifth cluster, Internal Hotel Chain Management, incorporates eighth ideas encompass- ing different factors related to operational questions and general hotel chain management issues.

- The sixth cluster, Strategic Quality Management, encompasses eighth ideas and refers to the implementation of a quality assurance philosophy and the hotel chain's encouragement of strategic behaviour to foment quality.

-The seventh cluster, Strategic Hotel Chain Management, consists of 13 ideas and includes factors related to strategic management, strategy planning and organizational values.

It is worth noting that clusters 2 and 3 are very close together on the point map. This fact is seen positively in terms of the methodology used given that the factors related to client management and strategic marketing management are highly related bearing in mind the value chain in service and hotel companies (Heskett et al. 1994; Vila 2004). The same occurs with clusters 4 and 5 , and 6 and 7 , which focus on similar issues though from different perspectives.

These seven clusters as well as the experts' rating of the ideas' importance are the final result of the concept mapping methodology. The data obtained are the fruit of the experts' opinions and, as such, they are subjective though processed objectively. Trochim (1989) proposes weighing the clusters obtained using the values obtained from the Likert scale. 


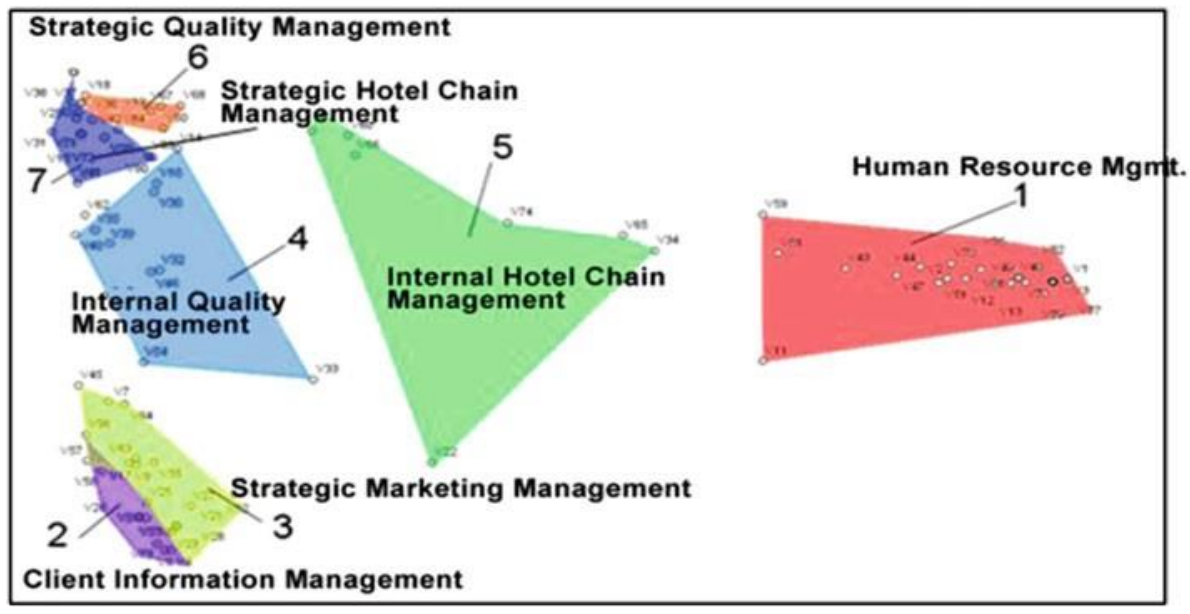

Fig. 5 Cluster map with labels. Source: The authors

However, in this study we have attempted to go further in terms of weighing or prioritising them, thus using the qualitative optimization technique described above (Sánchez et al. 2007).

We begin with the final list of $p=84$ ideas, resulting from the brainstorming carried out with the experts. The basic labels describing the individual evaluations belong to the orders-of-magnitude space OM (5) which corresponds to the Likert scale used. Each of the ideas was evaluated by $\mathrm{k}=8$ experts so that each idea is described by an 8-dimensional label.

As described in the previous section, the ranking process consisted of determining the optimal idea, $\mathrm{O}=(\mathrm{O} 1, \ldots, \mathrm{O} 8)$, and calculating the distance between each idea and the optimal one. As such, the greater the distance between the idea and the optimal idea, the lower the global evaluation for that idea regarding its impact on improving service quality. Less distance implies the opposite, that is, said idea has greater impact on improving service quality within the hotel chain. Based on the distance between each idea and the optimal one, we ordered the list of 84 ideas and determined their position based on this distance (Table 3). For ideas with the same distance, we repeated the algorithm for the corresponding subset to obtain a strict order of the ideas included in that set.

As explained above, this ordered list of relevant factors or aspects to manage service quality aims to serve as the first step towards building a specific quality management model for the hotel industry.

\section{Discussion and conclusions}

After analysing the literature in the hotel industry service quality area, the majority of which is dedicated to measuring service quality and developing general management models, we set our objective as determining which factors from Spanish hotel executives' points of view were the most important in terms of improving service quality. Given that this research deals with perceptions and opinions and that it is not based on a theory to be contrasted or quantified, we have opted to use qualitative methodologies. In this respect, we were also interested in providing a novel methodological proposal as is the case of combining techniques within the qualitative methodological framework, all the while guaranteeing maximum rigour in finding responses to the research question we considered. The techniques chosen for this purpose are concept mapping and qualitative optimization. 
Table 3 Extract of the first weighted list of ideas regarding their distance to the optimal value reference according to the experts participating in the concept mapping process

\begin{tabular}{llcc}
\hline Cluster & Ideas & $\mathrm{d}^{2}$ & Position \\
\hline C6 & 19 Existence of leadership for quality & 1 & 1 \\
C6 & 36 Commitment to quality at the executive level & 2 & 2 \\
C1 & 2 Specific training for the job post & 4 & 3 \\
C5 & 22 Internal communication & 4 & 3 \\
C2 & 56 Have an agile system to gather, process and resolve complaints & 4 & 3 \\
C7 & 18 Managers' commitment to the organisation & 6 & 4 \\
C1 & 1 Human resource motivation & 7 & 5 \\
C3 & 53 Client accessibility to information & 7 & 5 \\
C3 & 52 Be proactive regarding information for the client & 8 & 6 \\
C3 & 55 Be proactive with respect to the client & 8 & 6 \\
C7 & 41 Quality and environmental & 11 & 7 \\
& objectives with timing, deadlines & & \\
C4 & and measureable benchmarks & 12 & 8 \\
C4 & 32 Building and facilities management & 12 & 8 \\
C2 & 40 Establish quality measurement and tracking systems & 14 & 9 \\
C3 & 6 Process client data to segment them & 14 & 9 \\
C2 & 21 Corporate communications & 14 & 9 \\
C7 & 73 Use of own information regarding clients & 15 & 10 \\
\hline
\end{tabular}

Source: The authors

The debate regarding the use of mixed, quantitative and qualitative techniques in the same study is still alive today. On the one hand, the discussion recognises that each methodology's paradigms and objectives are distinct, and, as such, combining them does not seem very reasonable; on the other hand, others propose combining both focuses to overcome the deficits of each so long as the reach and the objectives of the remain clear (Sale et al. 2002). In Social Sciences and Management, in particular, qualitative methods are habitually used given the nature of the object being researched. However, it is in these fields where techniques have been proposed which include quantitative elements. In this study, we have combined concept mapping (Trochim 1989) and qualitative optimization (Sánchez et al. 2007) to be able to respond to our research question: "What management factors are considered as a priority to improve service quality among Spanish hotel chains?"

Concept mapping overcomes the disadvantages of qualitative techniques by objectifying a series of ideas generated by a group of experts. This technique is useful due to how it groups ideas together and represents them graphically. We feel concept mapping offers a series of advantages over other research methodologies, especially in terms of conceptualising the concept, including: the possibility of having the experts' opinions regarding an idea relatively quickly; data objectification due to techniques such as multidimensional scaling and cluster analyses of the opinions generated; the conceptual framework it provides according to the ideas and language the experts themselves use, thus better reflecting reality; its graphic representation of the ideas which make up the concept, making the latter and the inter-relationships between ideas easier to understand; and this graphic representation can be easily understood by both process participants and other groups interested in the research.

This technique is criticised in the same sense as other qualitative techniques: the sample used is not representative, the questionnaire is not clearly structured or the results obtained are "not standardised or reliable". However, this technique easily overcomes subjectivity issues found in other qualitative techniques (Bigné 2002). 
Our methodological proposal combines concept mapping with qualitative optimization, thereby improving the prioritisation and hierarchical ordering of the ideas obtained and structured. Instead of working with each cluster's average score in terms of importance (as defined within the concept mapping model), our contribution is based on prioritising these based on their distance to the optimal reference. This allows for experts' evaluations of each idea in terms of its importance to not be strictly quantitative, that is, the experts are not obligated to assign numbers to their evaluations; rather, they can assess ideas based on qualitative labels.

In terms of the specific management factors which improve service quality, according to Spanish hotel industry managers, our research results demonstrate 84 factors. After applying the multidimensional scaling and cluster analysis techniques, these are grouped into seven clusters related to management issues: human resources management, client information management, strategic marketing management, internal quality management, internal hotel chain management, strategic quality management, strategic hotel chain management. Based on the importance assigned to each of these, the existence of leadership and management's commitment to quality are the priority factors, both in the cluster referring to quality strategy management. These are followed by personnel training, internal communication (both reflecting an internal dimension) and having a system available to process complaints regarding client data management.

We are aware of the limits of this research in terms of how the primary data were obtained. The fact that we worked with a limited number of experts may imply having only obtained partial data, data which does not reflect the existing variety within the Spanish hotel industry. Similarly, result subjectivity is clear as the ideas expressed are opinions, though the techniques used have eliminated part of the researcher's subjectivity. Also, the results correspond to a concrete moment in time; if the study were carried out in another place or at another time, the results might be different.

The future research we foresee includes contrasting the ideas obtained with a representative sample of Spanish hotel chains and continuing our work on the design of a specific quality management model for hotels and hotel chains.

The methodology we propose, concept mapping + qualitative optimization, may be of great interest for other research which aims to generate a list of ideas, structure and prioritise them. A similar area of research would be to analyse results obtained from segmented hotel samples: rural hotels, boutique hotels, resorts, etc. Similarly, clients' opinions regarding service quality could be studied. In November 2009, we used this same combination of techniques to study the gap between the importance given to management factors affecting service quality and the degree of these same factors' development or implementation among a sample of rural hotels in Catalonia.

\section{References}

Agell, N., Piera, N.: Relacions qualitatives per al càlcul amb ordres de magnituds. Working Papers ESADE, 89, 2-10 (1992)

Agell, N., Rovira, X., Ansótegui, C., Sánchez, M., Prats, F.: Homogenising references in ordres of magnitude spaces: an application to credit risk prediction. In: Proceedings XIV International Workshop on Qualitative Reasoning. University Michoacana de San Nicolás de Hidalgo, México (2000)

Barth, M.C.: A low-cost, post hoc method to rate overall site quality in a multi-site demonstration. Am. J. Eval. 25(1), 79-97 (2004)

Beeril, A.: La metodología científica del Marketing y sus diferentes orientaciones. Investig. Mark. 43, 61-68 (1994) 
Bigné, E.: Una concepción ecléctica de la orientación al mercado y su escala de medición. Rev. Española Investigación Marketing 6, 33-57 (2002)

Bigné, J.E., Aldás-Manzano, J., Küster, I.,Vila, N.: The concept mapping approach in marketing: an application in the travel agencies sector. Qual. Mark. Res. 5(2), 87-95 (2002)

Bonoma, T.V.: Case research in marketing: opportunities, problems, and a process. J. Mark. Res. XXII, 199-208 (1985)

Calvo de Mora A., Criado F., Periáñez R.: Desarrollo de un instrumento para evaluar la idoneidad de los planes docentes: una aplicación a la diplomatura en turismo. Presented in Decisiones basadas en el conocimiento y en el papel social de la empresa. Academia Europea de Dirección y Economía de la Empresa, Palma de Mallorca (2006)

Camisón, C., Cruz, S., González, T.: Gestión de la calidad: conceptos, enfoques y sistemas. Pearson-Prentice Hall, Madrid (2007)

Easterby-Smith, M., Lowe, A.: Management Research: An Introduction. Sage, London (1991)

Eisenhardt, K.M.: Building Theories from Case Study Research. Acad. Manag. Rev. 14, 532-550 (1989)

Flick, U.: An Introduction to Qualitative Research. Sage, London (1998)

Goulding, C.: Grounded Theory. A Practical Guide for Management, Business and Market Researchers. Sage, London (2002)

Hair, J.F., Black, B., Babin, B., Anderson, R.E., Tatham, R.L.: Multivariate Data Analysis, 6th edn. Prentice Hall, Upper Saddle River (2006)

Harris, L.C., Piercy, N.F.: Management behavior and barriers to market orientation in retailing companies. J. Serv. Mark. 13, 113-131 (1999)

Heskett, J.L., Jones, T.O., Loveman, G.W., Sasser,W.E. Jr., Schlesinger, L.A.: Putting the service profit chain to work. Harvard Business Review, March-April, 105-11 (1994)

Jackson, K.M., Trochim,W.M.K.: Concept mapping as an alternative approach for the analysis of open-ended survey responses. Organ. Res. Meth. 5(4), 302-336 (2002)

Kruskal, J.B.:, Wish, M.: Multidimensional Scaling. Sage, London (1978)

Marshall, C., Rossman G.B.: Designing Qualitative Research. Sage, London (1989)

McKercher, B., Law, R., Lam, T.: Rating tourism and hospitality journals. Tour.Manag. 27, 1235-1252 (2006)

Miles, M.B., Huberman, A.M.: Qualitative Data Analysis: An Expanded Sourcebook. Sage, London (1994)

Morse, J.M.: Designing funded qualitative research. In: Denzin, N.K., Lincoln, Y.S. (eds.) Handbook of Qualitative Research, Sage, London (1994)

Nabitz, U., Severens, P., Brink, W., Jansen, P.: Improving the EFQM model: an empirical study on model development and theory building using concept mapping. Total Qual. Manag. 12(1), 69-81 (2001)

Oh, H.: Service quality, customer satisfaction, and customer value: a holistic perspective. Int. J. Hosp. Manag. 18, 67-82 (1999) 
Olorunniwo, F., Hsu, M.K., Udo, G.J.: Service quality, customer satisfaction, and behavioral intentions in the service factory. J. Serv. Mark. 20(1), 59-72 (2006)

Patton, M.Q.: Qualitative Research \& Evaluation Methods. Sage, London (2002)

Puig-Durán, J. Certificación y modelos de calidad en hostelería y restauración. Díaz de Santos, Madrid (2006)

Rosas, S.R., Camphausen, L.C.: The use of concept mapping for scale development and validation in evaluation. Eval. Program Plan. 30, 125-135 (2007)

Sale, J., Lohfeld, L., Brazil, K.: Revisiting the quantitative-qualitative debate: implicactions for mixed-methods research. Qual. Quant. 36, 43-52 (2002)

Sánchez, M., Hu, Y.C., Prats, F., Rovira, X, Sayeras, J.M., Dawson, J.: Ranking features by means of a qualitative optimization process. In: Proceedings $X$ Congrès internacional de l'Associació Catalana d'Intel.ligència artificial, Andorra (2007)

Santomà, R.: Aspectos de gestión en la calidad de servicio. Una aplicación del concept mapping al caso de las cadenas hoteleras en España. Doctoral Thesis. IQS Facultad de Economía, Ramon Llull University (2008)

Santomà, R., Costa, G.: Calidad de servicio en la industria hotelera: revisión de la literatura. Rev. Análisis Turístico 3, 27-44 (2008)

Simpson, B.: How Do Women Scientists Perceive Their Own Career Development?. Int. J. Career Manag. 6(1), 19-27 (1994)

Strauss, A., Corbin, J.: Basics of Qualitative Research. Techniques and procedures for Developing Grounded Theory. Sage, London (1998)

Travé, L., Dague, P.: Modèles et rasionnements qualitatifs. Lavoisier, Hermes Science, París (2003)

Trochim, W.M.K.: An introduction to concept mapping for planning and evaluation. Eval. Program Plan. 12, 1-16 (1989)

Trochim,W.M.K., Milstein, B.,Wood, B.J., Jackson, S., Pressler,V.: Setting objectives for community and Systems change: an application of concept mapping for planning a statewide health improvement initiative. Health Promot. Pract. 5, 8-19 (2004)

Vila, M.: Aportación al cuadro de mando integral para cadenas hoteleras. Estudio de ejes y variables críticas de actuación en el ámbito español. Doctoral Thesis, Departamento de marketing, operaciones y finanzas. ESADE - Ramon Llull University (2004)

Ward, J.H.: Hierarchical grouping to optimize an objective function. J. Am. Stat. Assoc. 58, 236-244 (1963)

Yampolskaya, S., Nessman, T., Hernández, M., Koch, D.: Using concept mapping to develop a logic model and articulate a program theory: a case example. Am. J. Eval. 25(2), 191-207 (2004) 